\title{
Pulsatile ocular blood flow in patients with low tension glaucoma
}

\author{
C B James, S E Smith
}

\begin{abstract}
Measurements of the intraocular pressure (IOP) pulse and pulsatile ocular blood flow (POBF) have been made in 22 patients with bilateral low tension glaucoma (LTG) and 29 healthy subjects matched as closely as possible for age, refractive error, IOP, systemic pulse pressure, and heart rate. Recordings were made in both the standing and supine positions. The amplitude of the intraocular pressure pulse was significantly lower in patients with LTG (1.2, SEM 0.1 mmHg standing, and 1.3 , SEM $0.1 \mathrm{mmHg}$ lying) than in healthy subjects $(1.9$, SEM $0.1 \mathrm{mmHg}$ standing, and 2.0 SEM $0.1 \mathrm{mmHg}$ lying): $p<0.001$ standing and $p<0.002$ lying. Measurement of POBF also showed a significant reduction between the healthy subjects (428 (31) SEM $\mu \mathrm{l} / \mathrm{min}$ standing and 345 (28) SEM $\mu \mathrm{l} / \mathrm{min}$ lying) and subjects with LTG (301 (27) SEM $\mu \mathrm{l} / \mathrm{min}$ standing and 249 (24) SEM $\mu \mathrm{l} / \mathrm{min}$ lying), $\mathbf{p}<0.005$ standing and $\mathbf{p}<0.02$ lying. This represents a difference of approximately $30 \%$ between the two groups in either posture. A close non-parametric correlation existed between the level of IOP and the POBF $(r=0.75$, $\mathrm{p}<0.001$ standing, and $\mathrm{r}=-0.55, \mathrm{p}<0.02$ lying). Such a correlation was not present in the healthy subjects. A reduction in POBF occurred in both groups on assuming the supine posture (healthy subjects 83 (16) SEM $\mu \mathrm{l} / \mathrm{min}$, LTG subjects 52 (17) SEM $\mu \mathrm{l} / \mathrm{min}$ ). These figures represent reductions of $19 \%$ and $17 \%$ respectively in comparison with the standing value. The results lend further confirmation to the hypothesis that vascular factors are associated with low tension glaucoma.
\end{abstract}

Low tension glaucoma (LTG) can be defined as the development of typical glaucomatous optic disc cupping and field damage in patients with normal iridocorneal angles and intraocular pressure (IOP) within the statistically normal range. Some regard the condition as separate from chronic open angle glaucoma (COAG), whereas others regard it as representing one end of the glaucoma spectrum. ${ }^{\prime}$ Much interest has centred on the vascular origins of LTG. In an extensive review Levene examined the role of systemic hypertension, generalised vascular disease, reduced ophthalmic artery pressure, and retinal vascular occlusion. ${ }^{2} \mathrm{He}$ concluded that the evidence of an association with any of these factors is at best uncertain. Subsequent work has confirmed this view. ${ }^{3}$

Better evidence exists for small vessel occlusion producing a sector infarct of the optic nerve linked to the presence of a splinter haemorrhage. ${ }^{2+}$ An increased incidence of migraine, ${ }^{56} \mathrm{a}$ reduced response of peripheral blood flow to cold, ${ }^{7}$ and a reduced compliance of the optic nerve head to a raised IOP measured by the visual evoked response ${ }^{8}$ have also been reported. Schulzer et al have recently suggested that in both LTG and COAG there may be two groups of patients - one with predominantly IOP related disease and one with vascular disease. ${ }^{9}$ These observations lend further corroboration to the theory that reduced perfusion, however caused, is at least a factor in the pathogenesis of LTG.

Clinically assessment of blood flow in the eye and optic disc has depended on the analysis of fluorescein angiograms. In both COAG and LTG hypofluorescence of the disc and prolonged fluorescein transit times have been reported. ${ }^{10-12}$ Hypofluorescence is more likely to be focal in LTG. ${ }^{10}$ A prolongation in transit time and choroidal filling have also been reported in patients with progressive LTG in comparison with those in whom the visual field defect did not appear to progress. ${ }^{13}$

An additional method for the examination of ocular pulsatile bloodflow is available. The ocular pressure pulse originates from blood filling the choroidal vasculature during cardiac systole. ${ }^{14}$ The intraocular pressure pulse has been observed to be reduced in patients with LTG. ${ }^{15}$ A method of analysis of the ocular pulse has been devised which converts the pressure pulse into a volume pulse, and with knowledge of the heart rate a measure of the pulsatile ocular bloodflow (POBF) can be calculated. ${ }^{16} 17$ As the choroidal and anterior optic disc circulations share a common source from the posterior ciliary arteries a reduction in choroidal circulation may well reflect a reduction in optic nerve head perfusion. Altered choroidal circulation is not, however, the only factor that will affect the intraocular pressure pulse. Additional factors include the initial level of IOP,${ }^{18}$ the systemic pulse pressure, ${ }^{19}$ and, as shown by recent work in this department, the ocular volume and the heart rate. The aim of this study was to measure the ocular pulse and the derived POBF in patients with LTG and compare the results with those obtained in a group of healthy volunteers matched as closely as possible for the factors outlined above.

\section{Material and methods}

\section{PATIENTS AND VOLUNTEERS}

Twenty-two patients, 12 male and 10 female, with bilateral LTG were examined in this study. Low tension glaucoma was diagnosed if the patient had typical glaucomatous cupping, glaucomatous field defects, normal iridocorneal angles on gonioscopy, and no IOP off treatment 
greater than $22 \mathrm{mmHg}$ during either day or 24hour phasing. No patient had any neurological deficit. One patient with a cataract extraction but no patients with trabeculectomy were included in this study. One patient was observed to have slight senile macular changes on fundal examination. Ten patients taking topical ocular hypotensive medication stopped this for two weeks prior to measurement. Two patients were taking systemic B adrenoceptor blocking drugs, one was taking systemic B adrenoceptor blocking drugs and isosorbide dinitrate, three were taking nifedipine, two were on thiazide diuretics, and two were on digoxin.

Twenty-nine healthy volunteers, six male and 23 female, on no medication and with no significant past ocular history, matched as closely as possible for age, refractive error, IOP, systemic pulse pressure, and heart rate, were measured as a control group. Table 1 outlines these variables for the two groups. Written consent was obtained from each subject after full explanation of the procedure had been given. Measurements were performed randomly in both groups between the hours of 0900 and 1800 .

\section{MEASUREMENTS}

Intraocular pressure and the ocular pulse were measured in both eyes with a pneumotonometer linked to a Langham Ocular Blood Flow System after instillation of local anaesthetic (benoxinate). Heart rate was determined simultaneously with an electrocardiograph (ECG). The POBF was calculated as previously described. ${ }^{2021}$

The blood pressure was recorded with an autosphygmomanometer (Takeda Medical) and an arm cuff level with the heart in both upright and supine postures. The mean blood pressure was calculated as diastolic pressure $+1 / 3$ of the pulse pressure.

The following protocol was observed for both groups of subjects. Refractive and slit-lamp examination and funduscopy were first performed on all subjects. Prior to measurement the subject rested seated for $\mathbf{1 0}$ minutes. This was followed by a period of 5 minutes standing. Measurement of blood pressure and pneumotonometric recordings were then made. The subject then lay down for 15 minutes using one pillow as a headrest, and the procedure was repeated. The pneumotonometer calibration was checked immediately before each patient was measured and at each change in posture.
Table 2 Mean (SEM) for the ocular variables measured in upright and supine postures

\begin{tabular}{|c|c|c|c|c|}
\hline & \multicolumn{2}{|c|}{ Healthy subjects } & \multicolumn{2}{|c|}{$L T G$ subjects } \\
\hline & Standing & Lying & Standing & Lying \\
\hline $\begin{array}{l}\text { Pulse amplitude } \\
\mathrm{mmHg}\end{array}$ & $1 \cdot 9(0 \cdot 1)$ & $2 \cdot 0(0 \cdot 1)$ & $1 \cdot 2(0 \cdot 1)$ & $1 \cdot 3(0 \cdot 1)$ \\
\hline $\begin{array}{l}\text { Pulse volume }(\mu \mathrm{l}) \\
\text { POBF } \mu \mathrm{l} / \mathrm{min}\end{array}$ & $\begin{array}{l}6 \cdot 0(0 \cdot 5) \\
428(31)\end{array}$ & $\begin{array}{l}5 \cdot 7(0 \cdot 4) \\
345(28)\end{array}$ & $\begin{array}{l}3 \cdot 9(0 \cdot 3) \\
301(27)\end{array}$ & $\begin{array}{l}3 \cdot 8(0 \cdot 34) \\
249(24)\end{array}$ \\
\hline
\end{tabular}

STATISTICAL ANALYSIS

Differences between subjects were assessed with unpaired $t$ tests. Within-subject differences were analysed with paired $t$ tests. Spearman's nonparametric regression analysis was used to determine the relationship between IOP and POBF in both groups.

\section{Results}

\section{DIFFERENCES BETWEEN GROUPS}

No significant difference was found between the right and left eyes in either of the two groups; thus only the results for the right eyes will be quoted. The results of the ocular pulse and POBF measurements are shown in Table 2. There was a significant difference in the amplitude of the ocular pulse between the two groups of $0.7 \mathrm{mmHg}$ standing and lying $(p<0.001$ standing, $\mathrm{p}<0.002$ lying) (Fig 1). Similarly the ocular pulse volume was significantly less in the LTG group by $2 \cdot 1 \mu \mathrm{l}$ standing and $1.9 \mu \mathrm{l}$ lying ( $p<0.001$ standing and $\mathrm{p}<0.01$ lying). The POBF was also significantly reduced in the patients with LTG, $127 \mu \mathrm{l} / \mathrm{min}$ standing and $96 \mu \mathrm{l} / \mathrm{min}$ lying $(\mathrm{p}<0.01$ and $\mathrm{p}<0.02 \mathrm{respec}-$ tively) (Fig 2). This represents a lower POBF in patients with LTG than was seen in healthy subjects of approximately $30 \%$ in either posture.

A significant non-parametric relationship existed between IOP and POBF in the subjects with LTG $(R=-0.75, \quad p<0.001$ standing, $R=0.55$, $p<0.02$ lying) (Fig 3). No such relationship was seen in the healthy subjects ( $R=0 \cdot 16$, NS standing, $R=0 \cdot 06$, NS lying) (Fig 4).

\section{POSTURAL DIFFERENCES}

There was a significant increase in IOP on assumption of the supine position (2.7 (SEM 0.3) $\mathrm{mmHg}, \mathrm{p}<0.001$ in the LTG subjects, and $2 \cdot 2$ (SEM 0.4 ) $\mathrm{mmHg}, \mathrm{p}<0.001$ in the healthy subjects), but the difference between the two

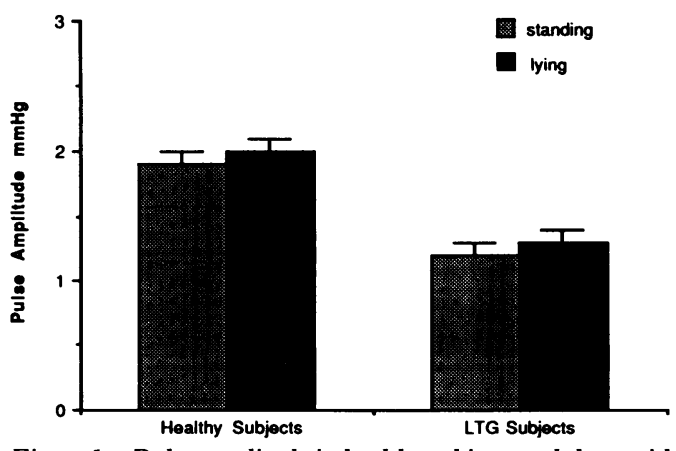

Figure 1 Pulse amplitude in healthy subjects and those with $L T G$ showing the effect of postural change.
Table 1 Characteristics of the two study groups

\begin{tabular}{|c|c|c|c|c|c|}
\hline & \multicolumn{2}{|c|}{ Healthy subjects } & \multicolumn{2}{|c|}{ Low tension glaucoma } & \multirow[b]{2}{*}{$p$} \\
\hline & Meàn (SEM) & Range & Mean (SEM) & Range & \\
\hline $\begin{array}{l}\text { Age }(\mathrm{yr}) \\
\text { Refraction (dioptres) } \\
\text { Standing IOP }(\mathrm{mmHg}) \\
\text { Lying IOP }(\mathrm{mmHg}) \\
\text { Standing MBP }(\mathrm{mmHg}) \\
\text { Lying MBP }(\mathrm{mmHg}) \\
\text { Standing SPP }(\mathrm{mmHg}) \\
\text { Lying SPP }(\mathrm{mmHg}) \\
\text { Standing HR (bpm) } \\
\text { Lying HR (bpm) }\end{array}$ & $\begin{array}{l}51(1 \cdot 8) \\
0(0 \cdot 3) \\
17 \cdot 4(0 \cdot 3) \\
19 \cdot 6(0 \cdot 6) \\
99(2) \\
90(2) \\
46(3) \\
47(2) \\
70(1) \\
59(1)\end{array}$ & $\begin{array}{l}29 / 73 \\
-5 \cdot 5 / 2 \cdot 7 \\
11 \cdot 4 / 23 \cdot 2 \\
13 \cdot 9 / 26 \cdot 8 \\
81 / 126 \\
75 / 125 \\
24 / 119 \\
24 / 94 \\
58 / 86 \\
48 / 74\end{array}$ & $\begin{array}{l}70 \cdot 3(2 \cdot 3) \\
-0 \cdot 3(0 \cdot 6) \\
17 \cdot 8(0 \cdot 5) \\
20 \cdot 5(0 \cdot 5) \\
105(3) \\
99(3) \\
54(4) \\
52(3) \\
79(4) \\
66(3)\end{array}$ & $\begin{array}{l}48 / 87 \\
-7 \cdot 75 / 4 \\
12 \cdot 4 / 21 \cdot 1 \\
15 \cdot 6 / 25 \cdot 4 \\
82 / 129 \\
80 / 130 \\
23 / 81 \\
31 / 78 \\
49 / 114 \\
48 / 93\end{array}$ & $\begin{array}{l}0.0001 \\
\text { NS } \\
\text { NS } \\
\text { NS } \\
\text { NS } \\
0.02 \\
\text { NS } \\
\text { NS } \\
0.02 \\
0.03\end{array}$ \\
\hline
\end{tabular}

$\mathrm{MBP}=$ mean blood pressure. $\mathrm{SPP}=$ systemic pulse pressure. $\mathrm{HR}=$ heart rate. 
Figure $2 P O B F$ in healthy subjects and those with LTG showing the effect of postural change.

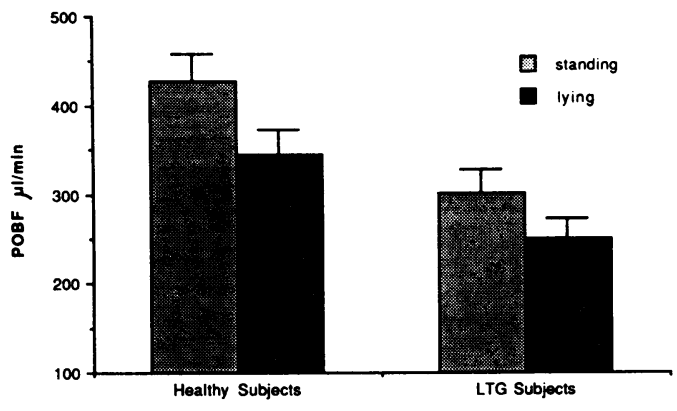

groups was not significant. The pulse amplitude in the LTG subjects increased slightly on lying $(0.1$ (SEM 0.1$) \mathrm{mmHg}, \mathrm{p}<0.05)$, but no other significant postural changes in the characteristics or derivatives of the ocular pulse was seen in either of the groups (Table 2). A reduction in POBF was seen on lying down in both healthy subjects (83 (SEM 16) $\mu \mathrm{l} / \mathrm{min} \mathrm{p}<0.001$ ) and in the LTG subjects ( 52 (SEM 17) $\mu \mathrm{l} / \mathrm{min}$, $\mathrm{p}<0.006)($ Fig 2$)$. This represented a reduction in flow of $19 \%$ and $17 \% \quad(p<0.001$ and $\mathrm{p}<0.006)$ respectively.

Postural changes occurred in both groups in mean blood pressure ( 9 (SEM 1$)$ mmHg healthy subjects $\mathrm{p}<0.001,6$ (SEM 2) $\mathrm{mmHg}$ in the LTG group $\mathrm{p}<0.002)$ and heart rate $(11($ SEM 1) bpm, $\mathrm{p}<0.001$ in healthy subjects, 13 (SEM 2) bpm, $\mathrm{p}<0.001$ in the LTG group). There was no significant postural change in the systemic pulse pressure.

\section{Discussion}

Our results show that there is an overall reduction in ocular pulse amplitude, pulse volume, and POBF in subjects with LTG in comparison with a normal volunteer control group. Previous measurements of the ocular pulse amplitude in LTG have been inconclusive. Perkins reported a reduction in the ocular pulse amplitude. ${ }^{15}$ Lambrou $e t$ al found no difference in the pulse amplitude but did find a reduction in pulse volume measurements in subjects with LTG. ${ }^{22}$ Comparison of ocular pulse measurements between groups is complicated by the numerous factors which may alter ocular pulse amplitude other than the pulsatile flow of blood into the choroidal vasculature. Initial IOP, ocular volume, and heart rate will all affect the size of the ocular pressure pulse. A correlation between

Figure 3 The relation between IOP and POBF in LTG subjects.

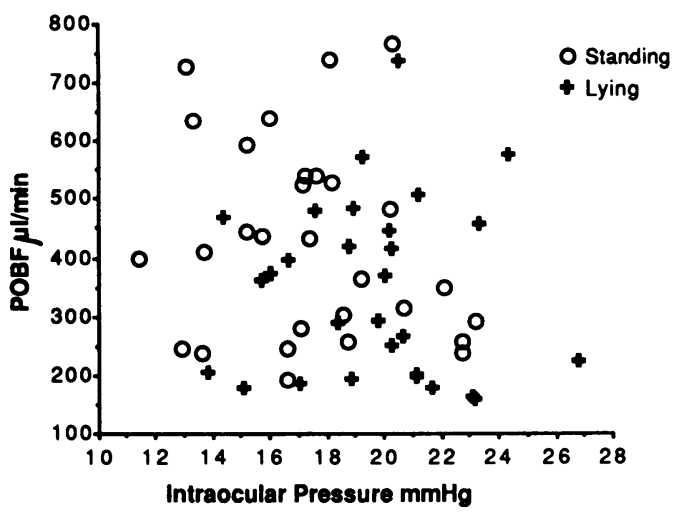

Figure 4 The relation between IOP and POBF in healthy subjects.

systemic pulse pressure and ocular pulse amplitude has also been reported. ${ }^{19}$ We have attempted to match these variables in the two study groups. Intraocular pressure in the two groups was similar. Refractive error was also similar. Refractive error if axial will be proportional to the length of the eye and hence if the eye is assumed to be spherical will be proportional to ocular volume. Tomlinson and Leighton ${ }^{23}$ found no significant difference in axial length between normal subjects and LTG patients with equivalent refractions. Matching for refractive error should ensure matching for ocular volume.

In our study the LTG subjects differed from their controls in two respects. First, they were older by 19 years. No significant changes in choroidal blood flow with age, by indocyanine green dye methods to measure blood flow, have been demonstrated unless macular degenerative changes are present. ${ }^{24}$ Only one LTG subject in this study had slight macular changes. An alteration in scleral rigidity will affect the size of the ocular pulse and calculations made from it. Slight changes do occur with age, though there is considerable variation. ${ }^{25}$ It is not likely that a change in scleral rigidity over the age difference seen here would be significant. Secondly, the LTG subjects had a slightly faster pulse rate (Table 1). This would tend to increase rather than reduce POBF but may reduce the amplitude of the pulse pressure. For the difference in heart rate observed the difference would be only small. It thus appears reasonable to assume that the observed differences between groups are not artifactually caused by differences in systemic or ocular factors not directly related to pulsatile ocular blood flow but reflect a real reduction in both the ocular pulse amplitude and POBF in patients with LTG. These results compare with measurements made in patients with COAG, where a reduction of $P O B F$ was found, though to a lesser degree, than were found in the LTG patients in this study. ${ }^{21}$

The importance of vascular factors in the aetiology of both LTG and COAG has been debated for many years. ${ }^{26-28}$ Pathologically there is a decrease in the vascularity of the optic disc in glaucomatous eyes. ${ }^{29}{ }^{30}$ It is impossible to know whether this is a result or cause of glaucomatous optic nerve damage, however. Much experimental work has centred on the effect of raised IOP as a means of altering the perfusion pressure of the optic nerve. ${ }^{31-3+}$ This suggests that optic 
nerve blood flow is not affected until the IOP is significantly raised - that is, the circulation displays autoregulation. Experiments in primates show that the chronic glaucoma model is associated with the same pattern of nerve fibre loss as is seen in human glaucoma. ${ }^{35}$ Studies with tritiated iodoantipyrine ${ }^{32}$ on this model have, however, failed to show a significant reduction in optic nerve blood flow. This work has been performed in previously healthy animal eyes, and care must be taken in interpreting the findings in the human glaucomatous eye, where, for example, autoregulation of optic nerve blood flow may be deficient or a reduction in optic nerve blood flow may be a second and independent factor in the aetiology of glaucomatous damage. Examination of the metabolic function of the optic nerve head ${ }^{36}$ has shown that relatively small changes in mean arterial pressure or increases in IOP may result in metabolic dysfunction of the optic nerve head which appear to be ischaemic in origin. Chronic reduction of ocular blood flow despite an IOP within the statistically normal range may thus result in metabolic or ischaemic damage to the optic nerve head. The finding in this study of a reduced POBF in LTG is therefore of great interest, as it suggests that eyes with LTG may indeed be susceptible to chronic metabolic dysfunction.

The measurement of POBF is essentially one of choroidal rather than anterior optic nerve blood flow. Although both circulations are derived from the posterior ciliary supply, ${ }^{37}$ caution must be used in drawing conclusions on anterior optic nerve blood flow from choroidal flow which appears not to demonstrate autoregulation. ${ }^{38} 39$ Measurement of pulsatile blood flow will also not take account of any nonpulsatile flow that may be present. Doppler studies have revealed moving blood in the ophthalmic artery during diastole,${ }^{40}$ though the extent to which such non-pulsatile flow contributes to total perfusion of the optic nerve head is at present unknown.

The close relationship between IOP and POBF seen in this study is also of particular interest (Fig 3). A relationship between asymmetric glaucomatous damage with asymmetric IOP has been reported, the eye with the higher pressure suffering the most damage. ${ }^{41-42}$ Our findings suggest that as well as a relatively elevated IOP these eyes may also suffer from a reduced pulsatile blood flow.

A postural reduction in POBF was seen in both groups of subjects. The relationship between pulsatile and non-pulsatile flow may also be affected by postural change, however. Perfusion pressure will alter on assumption of the supine posture. A rise in IOP and venous pressure and a fall in mean blood pressure (Table 1) will reduce perfusion pressure, but a larger fall in arterial hydrostatic pressure will increase perfusion pressure. An observed postural increase in ophthalmic perfusion pressure of $10 \mathrm{mmHg}^{43}$ fits well with these changes. An increase in the ophthalmic artery blood velocity during diastole has also been reported..$^{40}$ One might thus expect to see an increase in non-pulsatile flow in the supine position. The relationship for total blood flow is more complex, for this is also determined by pulse rate, which decreases in the supine position (Table 1). At decreased pulse rates not only would total blood flow fall but the proportion of pulsatile to nonpulsatile flow would be expected to increase. These complex relationships make it difficult to assess whether the fall in POBF reflects a postural fall in total blood flow or not. During sleep, however, when heart rate and mean arterial pressure fall further, an already reduced ocular circulation may be compromised.

\section{Conclusion}

Using a pneumotonometer linked to a Langham Ocular Bloodflow system we have recorded the ocular pulse in a group of subjects suffering from LTG and a carefully matched control group. Using previously established techniques we have derived a measure of the POBF in both groups. A significant reduction in both the ocular pulse amplitude and the POBF has been found in patients suffering from LTG. In both groups there was a significant reduction in POBF on lying. In LTG subjects a close correlation between IOP and POBF was found. These results lend further weight to the theory that vascular factors are associated with the development of LTG and critical underperfusion is causative of damage to the optic nerve head, particularly when the subject is supine. Further research to elucidate the effect of reducing IOP on blood flow in these patients and to determine methods of improving ocular blood flow may be helpful in treating this condition.

We thank Mr M Falcon at St Thomas's Hospital, Mr R Coakes at King's College Hospital, and Mr R Hitchings at Moorfields Eye Hospital for allowing us to study their patients. Karen Clark and Raymond Allen kindly provided technical help. CBJ is supported by the special trustees of St Thomas's Hospital. Financial support by the special trustees of St Thomas's Hospital. Financial support for the study was also kindly provided by the Royal National
Institute for the Blind. The Langham Ocular Bloodflow System Institute for the Blind. The Lang
was donated by Dispersa UK Ltd.

1 Drance SM. Low tension glaucoma: enigma and opportunity Arch Ophthalmol 1985; 103: 1131-3.

2 Levene RZ. Low tension glaucoma: a critical review and new material. Surv Ophthalmol 1980; 24: 621-63.

3 Carter CJ, Brooks DE, Doyle DL, Drance SM. Investigations into a vascular etiology for low tension glaucoma. Ophthalmology 1990; 97: 49-55.

4 Drance SM. Disc haemorrhages in the glaucomas. Surv Ophthalmol 1989; 33: 331-7.

5 Corbett JJ, Phelps CD, Eslinger P, Montague PR. The neurologic evaluation of patients with low tension glaucoma. Invest Ophthalmol Vis Sci 1985; 26: 1101-4.

6 Phelps CD, Corbett JJ. Migraine and low tension glaucoma. Invest Ophthalmol Vis Sci 1985; 26: 1105-8.

7 Drance SM, Douglas GR, Wijsman K, Schulzer M, Britton RJ. Response of blood flow to warm and cold in normal and low-tension glaucoma patients. Am $\mathcal{F}$ Ophthalmol 1988; 105 : 35-9.

8 Pillunat LE, Stodtmeister R, Wilmanns I. Pressure compliance of the optic nerve head in low tension glaucoma. $B r \mathcal{F}$ Ophthalmol 1987; 71: 181-7.

9 Schulzer M, Drance SM, Carter CJ, Brooks DE, Douglas GR, Lau W. Biostatistical evidence for two distinct chronic open angle glaucoma populations. Br $\mathcal{F}$ Ophthalmol 1990; 74: angle glauc

10 Hitchings RA, Spaeth GL. Fluorescein angiography in chronic simple and low tension giaucoma. Br $\mathcal{F}$ Ophthalmol 1977; 61: 126-32.

11 Spaeth GL. Fluorescein angiography: its contribution towards understanding the mechanisms of visual loss in glaucoma Trans Am Ophthalmol Soc 1975; 73: 491-553.

12 Hayreh SS, Walker WM. Fluorescent fundus photography in glaucoma. Br 7 Ophthalmol 1967; 63: 982-9.

13 Geijssen HC, Greve EL. Vascular risk factors in progressive low tension glaucoma. In: Krieglstein GK, ed. Glaucoma update III. Berlin: Springer, 1987: 77-83.

14 Bynke HG, Schele B. On the origin of the ocular pulse. Ophthalmologica 1967; 153: 29-36.

15 Perkins ES. The ocular pulse. Curr Eye Res 1981; 1: 19-23.

16 Langham ME, Farrell RA, O'Brien V, Silver DM, Schilder P. Blood flow in the human eye. Acta Ophthalmol (Kbh) 1988; Blood flow in the hum 
17 Silver DM, Farrell RA, Langham ME, O'Brien V, Schilder P. Estimation of pulsatile ocular blood flow from intraocular pstimation of pulsathe ocular bio opd (suppl 191): 25-9.

18 Eisenlohr J, Langham ME, Maumenee AE. Manometric studies of the pressure/volume relationships in living and enucleated eyes of individual subjects. Br $\mathcal{F}$ Ophthalmol 1962; 46: 536-48.

19 Bron AJ, Knox DL, Gaasterland D. Tonographic studies in carotid occlusive disease. Brf Ophthalmol 1967; 51: 577-95.

20 Trew DR, Smith SE. Postural studies in pulsatile ocular blood flow: I. Ocular hypotension and normotension. $B r^{\prime} \mathcal{F}$ Ophthalmol 1991; 75: 66-70.

21 Trew DR, Smith SE. Postural studies in pulsatile ocular blood flow: II. Chronic open angle glaucoma. Brf Ophthalmol 1991; 75: 71-5.

22 Lambrou GN, Sindhunata P, van den Berg, Geilssen $\mathrm{CH}_{\text {, }}$ Vyborny P, Greve EL. Ocular pulse measurements in low tension glaureve In: Leds. Ocular bloodflow in glaucoma. Amsterdam: Kugler and Ghedini, 1989: 115-20.

23 Tomlinson A, Leighton DA. Ocular dimensions in low tension glaucoma. Br F Ophthalmol 1972; 56: 97-105.

24 Prunte C, Niesel P. Quantification of choroidal bloodflow parameters using indocyanine green video-fluore angiography and statistical picture analysis. Graefes Arch Clin Exp Ophthalmol 1988; 226: 55-8.

25 Friedenwald JS. Contribution to the theory and practice of tonometry. Am f Ophthalmol 1937; 20: 985-1024

26 Quigley HA. Optic nerve head blood flow is normal in chronic experimental glaucoma. In: Krieglstein GK, ed. Glaucoma Update III. Heidelberg: Springer, 1987: 47-50.

27 Hayreh SS. Factors determining the glaucomatous optic nerve head damage. In: Krieglstein GK, ed. Glaucoma Update III. Berlin: Springer, 1987: 40-6.

28 Anderson DR. Circulation and axonal transport in the optic nerve. Trans Ophthalmol Soc UK 1976; 96: 345-7.

29 Cristini G. Common pathological basis of the nervous ocular symptoms in chronic glaucoma. Br f Ophthalmol 1950; 35: $11-20$.

30 François J, Neetens A. Vascularity of the eye and the optic nerve in glaucoma. Arch Ophthalmol 1964; 71: 219-25.
31 Quigley HA, Flower RW, Addicks EM, McLeod DS. The mechanism of optic nerve damage in experimental acute intraocular pressure elevation. Invest Ophthalmol Vis $S c i$ 1980; 19: 505-17.

32 Quigley HA, Hohman RM, Sanchez R, Addicks EM. Optic nerve head bloodflow in chronic experimental glaucoma. Arch Ophthalmol 1985; 105: 956-62.

33 Geijer C, Bill A. Effects of raised intraocular pressure on retinal, prelaminar, laminar, and retrolaminar optic nerve blood flow in monkeys. Invest Ophthalmol Vis Sci 1979; 18: $1030-42$.

34 Ernest JT. Optic disc blood flow. Trans Ophthalmol Soc UK 1976; 96: 348-51.

35 Quigley HA, Hohman RM, Addicks EM, Green WR. Blood vessels of the glaucomatous optic disc in experimental primate and human eyes. Chronic glaucoma. Invest Ophthalmol Vis Sci 1984; 25: 918-31.

36 Novack RL, Stefansson E, Hatchell DL. Intraocular pressure effects on optic nerve-head oxidative metabolism measured in vivo. Graefes Arch Clin Exp Ophthalmol 1990; 228: in vivo.

37 Hayreh SS. The ophthalmic artery: II. Branches. $\mathrm{Br} f$ Ophthalmol 1962; 46: 212-47.

38 Bill A, Sperber GO. Control of retinal and choroidal blood flow. Eye 1990; 4: 319-25.

39 Nagasubramanian S. Combined reflectometric and photographic study of the retinal and choroidal circulation at increased IOP. Trans Ophthalmol Soc UK 1977; 97: 177-84.

40 Canning CR, Restori $M$. Doppler ultrasound studies of the ophthalmic artery. Eye 1988; 2: 92-5.

41 Cartwright MJ, Anderson DR. Correlation of asymmetric damage with asymmetric intraocular pressure in normaldamage with asymmetric intraocular pressure in normal1988; 106: 898-900.

42 Crichton A, Drance SM, Douglas GR, Schulzer M. Unequal intraocular pressure and its relation to asymmetric visual field defects in low-tension glaucoma. Ophthalmology 1989; 96: 1312-4.

43 Weiglin E, Niesel P. Der Netzhautarteriendruck bei Anderung der Korperlage. Graefes Arch Clin Exp Ophthalmol 1950; 150: 374-84. 